Article

\title{
Location Choice of Overseas High-Level Young Returned Talents in China
}

\author{
Haining Jiang ${ }^{1} \mathbb{D}$, Wenzhong Zhang ${ }^{2,3}$ and Jian Duan ${ }^{1, *}$ \\ 1 College of Geography and Environmental Sciences, Zhejiang Normal University, Jinhua 321004, China; \\ jhn841263@zjnu.cn \\ 2 Key Laboratory of Regional Sustainable Development Modeling, CAS, Beijing 100101, China; \\ zhangwz@igsnrr.ac.cn \\ 3 Institute of Geographic Science and Natural Resources Research, CAS, Beijing 100101, China \\ * Correspondence: duanj@zjnu.edu.cn
}

Received: 15 October 2020; Accepted: 2 November 2020; Published: 5 November 2020

check for updates

\begin{abstract}
International talent's mobility has increased over the last decade, especially in the wake of globalization and knowledge economy. China no longer exclusively shows an asymmetrical flow to developed countries, but it often turns out to be the most desirable destination of brain circulation for some overseas high-level young returned talents. In this context, based on the data obtained from the "Thousand Youth Talents Plan" (2011-2016) publicized by the Central Millennium Plan Office, the methods of the Moran's I index, the Getis-Ord Gi* index, and the Poisson regression model are adopted in this study to analyze the location choice of overseas high-level young returned talents in China and its driving factors. The spatial configuration shows up that the United States is the most important origin overseas and China's municipalities or provincial capitals are the most remarkable destinations. Moreover, the analysis reveals the distribution by academic majors is uneven, which may be caused by knowledge priority and legacies of China's Soviet-style innovation system. The main analysis is extended with the Poisson regression model to estimate the significance of the influence factors. The empirical results show that the factors in order of importance are academic opportunity, urban amenity, and place attachment. Concretely, the most important factors for location choice of overseas high-level young returned talents, namely research and development $(R \& D)$ investment, internal convenience and hierarchy level in science and technology (S\&T) system, external accessibility, transportation accessibility, university endowment, and health care are the substantial secondary factors, while place-oriented talent agglomeration and prior alumni connection play a minor role.
\end{abstract}

Keywords: spatial distribution; high-level young returned talent; location choice; China

\section{Introduction}

Human capital is one of the main driving forces of innovation as well as regional and national competitiveness. High-level talent (i.e., professors and postdocs) is a small but increasingly important fraction of core human capital in the era of knowledge economy [1,2]. In particular, returned talent's migration from more to less developed economies is a vital carrier of technology transfer and global innovation systems [3]. They form a key link for the catch-up strategy of developing countries; therefore, the topic has received widespread attention in the international migration and innovation-related disciplines $[4,5]$.

Since the mid-1990s, especially during the so-called "war" or "race" for talent, the volume and diversity of Chinese returnees have increased. Hereinto, the circumfluence of overseas high-level young returned talent is critical. Correspondingly, the Chinese central government hence published 
the "Thousand Youth Talent Plan" in 2008, which consists of several categories and offers significant financial support to recruit the outstanding professors and scholars back to China [6], to conduct research in high-tech industries or in new fields at the frontiers of science, or to participate in major Chinese scientific projects, key laboratories et al. As a result, China is no longer the world's largest brain drain but the most desirable destination, remolding competitive abilities in international situations $[7,8]$. Furthermore, China's domestic innovation has been gradually improving [9]; some major Chinese cities gradually move up the hierarchical level within the global city network [10].

In this context, there has been a burgeoning research on the dynamic and location choice over the recent decades. The traditional debate has framed the push-pull model on the return choice [11]. The model aims at a comprehensive understanding of residential location and its implications that considers embedded social factors, individual preferences, and career trajectories [12,13]. Subsequently, various attempts on the circumfluence of overseas high-level returned talents have been involved in a broader discussion to emphasize the important role of economic factors and some other factors, such as environment, climate, insurance, and infrastructure et al. [14-16]. Although there is a heated debate among different research results, an agreement has been reached that the circumstance of overseas high-level young returned talents is balancing the career prospects versus psychic comfort, which is involved into geographical proximity to family and social proximity to cultural values, Chinese in particular.

However, there are several limitations in the literature regarding the relationship between return locations of overseas high-level young returned talent and their dynamics. On one hand, existing studies focus on the field of pedagogy and demology, and the research on the spatial pattern of overseas high-level young returned talents is inadequate and especially scarce from a geographical perspective. On the other hand, there is a lack of comprehensive and systematic analysis on the driving factors that affect high-level returned talents' location choices in China, in particular the missing consideration of personal social factors.

Therefore, there is a need to further explore how young high-level returned talent chooses return locations in China and their spatial structure at the city scale. The analysis results of this study will contribute to a better understanding of the spatial structure of city hierarchy driven by high-skilled human capital in particular and emerging economies in general. For this purpose, this study uses the data on overseas high-level young returned talent obtained from the website http://www.1000plan.org, which is vital to China's talent program. The Moran's I index, the Getis-Ord Gi* index, and the Poisson regression model are employed in this study to analyze the location character of overseas high-level young returned talents, and its driving factors.

The paper is organized as follows. Section 2 critically evaluates the China-related and high-level talents literature that drives the empirical analysis. Section 3 provides a brief introduction to the research design and data sources. Sections 4 and 5 focus on the empirical analysis and provide a reasonable explanation of the results. Conclusions and implications for further research are discussed in the final section.

\section{China-Specific Factors Affecting the Location Choices of Overseas High-Level Returned Young Talent}

In fact, the concept of overseas high-level young returned talent can be included in the general theory that argues that the group in higher ranks of the social hierarchy, who have better living standards and a stronger impact on social and scientific development. In recent times, the research has witnessed growing interest in the migration of overseas high-level young talent [17], which has been preoccupied with the question of how the role of economic, social, and cultural capital in shapes the location decisions [18]. Studies using concepts and models such as push-pull model [19], brain circulation [20], academic mobility [21], and place attractiveness [22] employ a variety of terms to discuss the return decisions and its significance of the effect in the destination regions. It is no doubt that the return-migration decision of overseas high-level young talent can be in essence constituted 
of a dynamic interface of professional and personal factors [6,10,23] — that is the result of rethinking about the social advantages versus academic benefits from living in China, which involves three main aspects: (1) quality of life named urban amenity, (2) academic development opportunities, and (3) place attachment.

\subsection{Urban Amenity and Location Choice}

Thus far, an agreement has been reached that as an identical specification of life quality, amenity-led factors play a more significant role in affecting the intentions of individuals in cities' choice [24,25]. For example, with the help of net migration data for 133 European regions between 1990 and 2006, Rodriguez-Pose and Ketter (2012) analyzed the important influence of regional amenity on location choice, showing a kind of place-based preference [26]. Moreover, Frenkel and Bendit (2013) figured out the most important factors for residential location choice of knowledge-workers, namely municipal socioeconomic level, housing affordability, and commuting time, while cultural and educational land-use and culture-oriented lifestyle are the substantial secondary factors [27].

The spatial location choice of Chinese overseas high-level young returned talent is no doubt a phenomenon of population movement [28]. A few studies have focused on the role of city amenities in determining the migration behavior and intentions. In particular, on the debate of job opportunities versus urban amenities in determining the locational choice, Su et al. (2019) employed a conditional logit model on China's internal migrants and found out urban amenities are more crucial [29]. Shao and Chen (2014) found that a good health care environment in the region is conducive to ensure and improve the labor output [30], which is an important guarantee variable for overseas high-level young returned talents to fulfill their life demands. Du and Peng (2017) concluded that transportation infrastructure can compress space-time distance, improve regional traffic accessibility, and promote its attraction to overseas returnees. Generally, the better transportation accessibility is highly correlated with high-quality and convenient services for talents' innovation and life [31]. Meanwhile, it can also save time and economic costs. Chen (2020) found that airports are an important point of movement and station for foreign traffic, as well as subways, which are an important means of transportation of talent exchange and cooperation, production, and living within a city [32]. If a city has built a subway, the better the accessibility in the area, the more attractive for talents make a decision [33].

As a whole, cities with higher indices of quality of life tended to attract more high-level young returned talents [34], including education resource for their children, social insurance, residential housing, and relatively well-developed infrastructure. Especially due to the large discrepancies, the most attractive cities in China are located in east developed urban agglomerations [4], the less developed cities in western region, compared to its counterparts in more cosmopolitan cities, are in a disadvantaged position with regards to attracting high-level returned talent [35]. On the basis of the literature, the study posits that:

Hypothesis 1 (H1). Chinese overseas high-level young returned talent will be more likely to search for the cities with better amenity.

\subsection{Academica Opportunity and Location Choice}

There are numerous factors behind academic opportunities and location choices of Chinese overseas high-level young returned talent, including prospective R\&D resources, technological policy, and career platform. For example, $\mathrm{Xu}$ and Guo (2019) have confirmed that the increase in R\&D funding intensity has a significant attractive effect on regional scientific and technological talents [36]. Besides, domestic well-known universities or research institutions possess the higher organizational and academic reputation, which is the most important career platform for overseas high-level young talents. Liu et al. (2017) insisted that the region that can provide more and higher career platforms will show great advantages to gather experts [37]. The roles of these factors have been the primarily and prevalently career-related drivers, which is an economic and institutional environment that may 
affect the behaviors in the process of making and fulfilling relocation decisions [38]. Obviously, the professional opportunity is highly positive correlation by China's hierarchical science and technology (S\&T) system [39], with ample resource and premium research organizations.

China's major breakthrough in reforming its S\&T system occurred in 1985 [40], which was once designed in accordance with the Soviet concept, and has transformed it to meet the expectations of a modernized economy. Simultaneously, innovation policy has developed in a similar direction, shifting its emphasis from importing technology to the need for collaboration and innovation [41]. Specifically, in the early 1980s, public research institutes conducted $R \& D$ and were built near state-owned enterprises in several industrial bases, which led to a dominance of rather static, government-organized systems [42]. With the reform of China's S\&T sector, significant restructuring of public research institutes and a broadening of functions for universities have changed the former trends considerably [43]. China has thus established leading research universities that are capable of carrying out basic and applied R\&D and can play a major role in national innovation systems [44]. Moreover, recent research has underpinned two vital notions that concern the spatial character of China's S\&T system. First, the system has a strong hierarchical order, with Beijing and its science organizations dominating the national system and functioning as a hub [45]. Second, the government and its involvement in arranging R\&D is a highly correlated factor [46]; cities in the medium ranks of the system are changing their positions significantly, represented by the other municipalities and some provincial capital.

Generally, the existed studies have confirmed that China's high-level young returned talents tend to cluster in high-level cities, which correlated with the relative richer innovation resources [47]. On the basis of the literature, the study posits that:

Hypothesis 2 (H2). Chinese overseas high-level young returned talents will be more likely to search for better career platform or higher hierarchical city in S\&T system.

\subsection{Place Attachment and Location Choice}

Place attachment is accumulated within Chinese overseas high-level young returned talent's mobility, and inevitably endows cultural and social comparative advantage over peers [48]. Generally, place attachment can be understood as guanxi or embeddedness with a city and institution, in terms of kinships, alumni (schoolmates or classmates), birthplace, etc. [49], which is connected with social proximity as Boschma (2005) proposed and likely to constrain and enable the relocation decision [50]. For example, Gu et al. (2019) employed the data from the 2015 national one percentage population sample survey and figured out that social network linkages exert a vital role on location choice [51]. As far as the Chinese overseas high-level young returned talent are concerned, the guanxi network is composed of mostly professional associations organized by the connection in academic, technological, and other common interests that are of great significance for the returnees to obtain a chance, in the case of premium universities or research institutions in particular.

Owing to the positive correlation with trustworthiness, alumni connection and its involvement with path dependence is a crucial factor [49,51]. Prior research has suggested that most high-level young returned talent who graduated from top universities in the world or/and had domestic education experiences, which can be part of primordial ties. Empirical evidence research on the return choice of social factors has shown that the alumni community played a central role, which can be managed at the beginning in a new environment that requires personal connections to overcome the challenge [7]. Generally, the closer relationship between involved people and organizations, the higher the probability of a long-term cooperation and further transnational decision is. In addition, the choices people have made in the past will determine the choices in the future; once the system enters a path, whether that path is good or bad, it will continue to develop along that path [52]. There is a "Matthew effect" feature in the talent distribution character; that is, the more regional talents gather, the stronger the attraction to the new and potential high-level young talents, and finally raised up the centrality [53] and magnetic field effect [54]. On the basis of the literature, the study posits that: 
Hypothesis 3 (H3). Chinese overseas high-level young returned talents will be more likely to search for the cities with deeper connection or higher familiarity.

\section{Data Sources and Methods}

\subsection{Data Sources}

This study uses the detailed information of qualified candidates of the "Thousand Youth Talents Plan" published by the Central Millennium Plan Office, which aims to provide the backbone for leapfrog development in science, technology, and industry. Several steps were carried out for data preparation, as listed below.

First, the basic qualification requirements of outstanding overseas high-level young returned talent are that the candidates should be younger than 40 years old and have a doctoral degree in natural sciences, engineering, or technology. Meanwhile, they should have at least three years of post-doc research or professional experience in renowned overseas universities, research structures, or enterprises. The analysis is confined to the plan's duration between 2011 and end of 2016. In sum, there were eight announcements during six years, and 2846 overseas high-level young returned talents in total, who are concentrated in universities $(81.57 \%)$, research institutes $(18.05 \%)$, and enterprises $(0.38 \%)$. As far as university is concerned, what needs to be pointed out is that 985 and 211 projects were initiated to build some world-class universities in China; 39 and 112 universities were chosen respectively. The universities in 985 project are normally the elite ones in 211 project, $66.22 \%$ and $8.52 \%$ of overseas high-level young returned talents choose to work these universities in the two projects, while the other colleges and universities' proportion occupy only $6.81 \%$. (Table 1).

Table 1. The proportion and career platforms of overseas high-level young returned talents in China.

\begin{tabular}{cccccc}
\hline & \multicolumn{3}{c}{ University } & Research Institutes & Enterprises \\
& 985 Project & $\begin{array}{c}\text { 211 Project } \\
\text { (Except 985) }\end{array}$ & Others & & \\
\hline Sum & 1896 & 244 & 195 & 517 & 11 \\
Proportion (\%) & 66.22 & 8.52 & 6.81 & 18.05 & 0.38 \\
\hline
\end{tabular}

Additionally, their spatial distribution is defined by countries where they studied overseas and returned to work in China. Thus, the units of geographical analysis are overseas countries and Chinese cities. In China's urban administrative system, cities in the province-level units are classified into four categories and have corresponding administrative ranks: municipalities that are directly administered by the central government include Beijing, Shanghai, Tianjin, and Chongqing; sub-province-level cities that are a half-level lower than municipalities and a half-level higher than prefecture-level units; prefecture-level cities refer to provincial capitals and cities with districts; and cities without districts, known as county-level cities. In sum, 264 county-level cities were selected as the research units.

As shown in Figure 1, the overall backflow path of overseas high-level young returned talent in China displays a relatively stable spatial structure. The most important sources of overseas high-level young returned talent are the United States (65.07\%), followed by Germany $(6.01 \%)$, the United Kingdom (5.69\%), Singapore (4.09\%), Japan (3.25\%), and Canada (2.97\%). In terms of talent destinations in China, Beijing and Shanghai comprise the larger share $(23.89 \%$ and $16.31 \%$, respectively), followed by Wuhan (7.02\%), Nanjing (6.85\%), Hangzhou (5.94\%), Hefei $(5.90 \%)$, and Guangzhou (5.27\%). In sum, the overseas high-level young returned talent during 2011 to 2016 renders a spatial structure where "United States-Beijing" and "United States-Shanghai" comprise the dual-core axis, and "United States-Wuhan," "United States-Nanjing," "United States-Hangzhou," "United States-Hefei", and "United States-Guangzhou" comprise the secondary axis. 


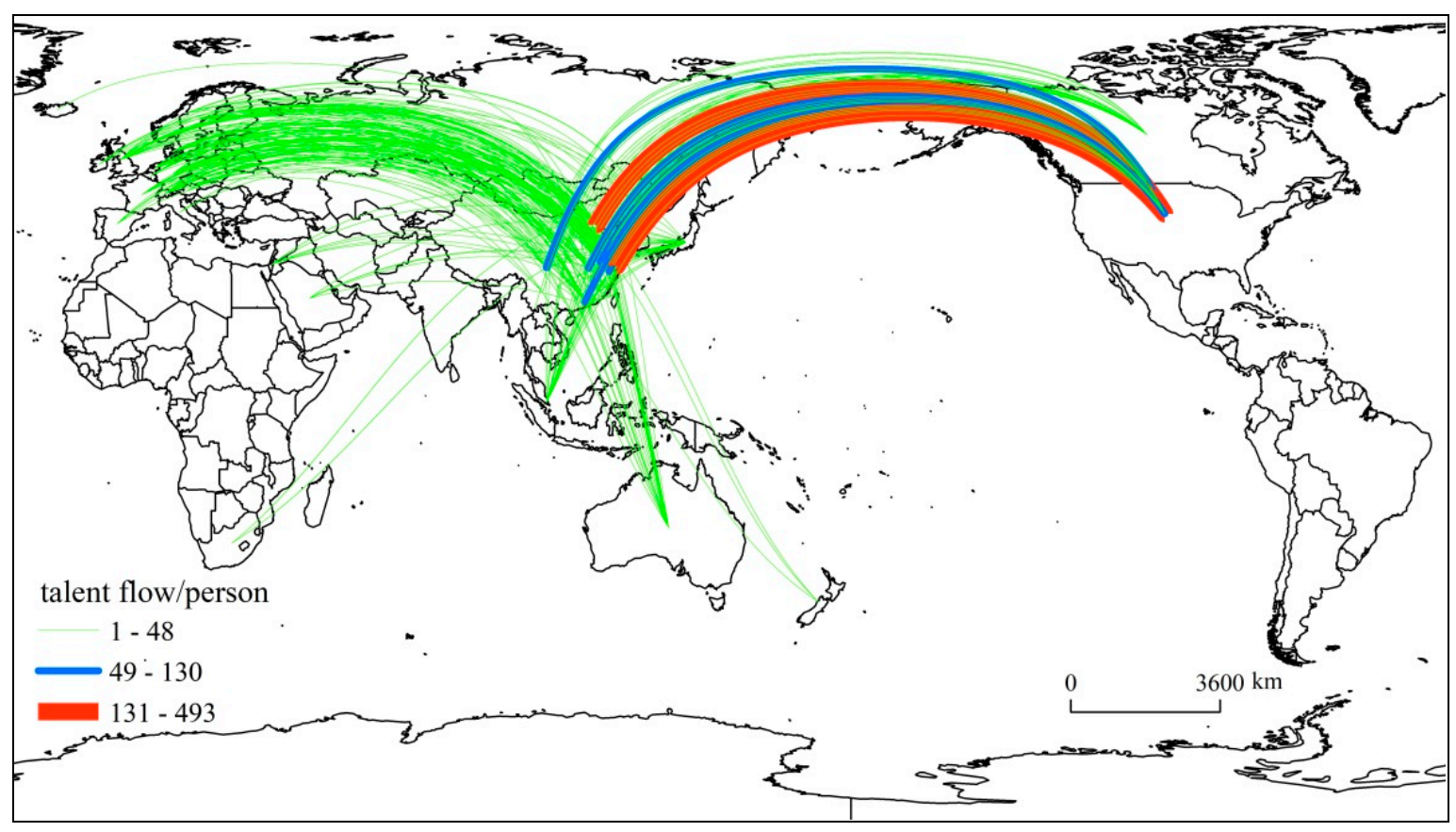

Figure 1. The return path of overseas high-level young returned talents in China (2011-2016).

Moreover, individual information can help to gain further insight on the driving factors, which are thus two sides referred to as place attachment: alumni and talent agglomeration. The former includes if the candidate has the prior study experience in the chosen returned academic institute or/and university; and the latter consists of the overlap between path dependence and workplace, which involves into the municipalities and province-level unites in the China's urban administrative system. The individual information was got through personal social website, homepages of university or research institute, as well as information from research papers. The missing one was improved and collated through consultations by telephone and email.

\subsection{Research Methods}

\subsubsection{Moran's I Index}

Moran's I index was used to examine the relationship between similarity, dissimilarity (positive and negative spatial correlation), and mutual independence among the distribution of high-skilled talent in different cities. The value of Moran's I ranges from -1 to 1 . When close to 1 , it indicates a strong trend of a homogeneous cluster, and when close to -1 , a heterogeneous cluster. However, a value close to 0 implies random distribution or no spatial correlation. The formula is given as:

$$
\mathrm{I}=\frac{N \sum_{i} \sum_{j} w_{i j}\left(x_{i}-\bar{x}\right)\left(x_{j}-\bar{x}\right)}{\left(\sum_{i} \sum_{j} w_{i j}\right) \sum_{i}\left(x_{i}-\bar{x}\right)^{2}}
$$

where $N$ is the total number of cities, $w_{i j}$ represents the spatial weight, $x_{i}$ and $x_{j}$ represent the attribute values of city $i$ and city $j$, respectively, and $\bar{x}$ is the average attribute value of all cities. The significance test of Moran's I was conducted by the $z$ test.

$$
Z(I)=\frac{I-E(I)}{\sqrt{\operatorname{Var}(I)}}
$$

where $E(I)$ is the mathematical expectation, and $\operatorname{Var}(I)$ is the variance. 


\subsubsection{Hot Spot Analysis (Getis-Ord Gi}

Subsequently, the hot spot analysis employed Getis-Ord Gi* statistics to produce a hot and/or cold spot map. A high positive z-score and a small $p$-value for a feature (talent agglomeration or premium location in this case) indicate a spatial clustering of high values (a hot spot). A low negative z-score and a small $p$-value indicate spatial clustering of low values (a cold spot). A z-score near zero indicates no apparent spatial clustering. The Getis-Ord $G i^{*}$ is formulated as:

$$
G_{i}^{*}=\frac{\sum_{j}\left(w_{i j} x_{j}\right)}{\sum_{j} x_{j}}
$$

To compare and interpret, the index of Getis-Ord $\mathrm{Gi}^{*}$ is standardized. The expression is as follows:

$$
Z\left(G_{i}^{*}\right)=\frac{G_{i}^{*}-E\left(G_{i}^{*}\right)}{\sqrt{\operatorname{Var}\left(G_{i}^{*}\right)}}
$$

where $E\left(G i^{*}\right)$ and $\operatorname{Var}\left(G i^{*}\right)$ are the mathematical expectation and variance of $G i^{*}$, respectively, and wij represents the spatial weight. A positive and highly significant $Z\left(G i^{*}\right)$ value demonstrates regions clustered with high attribute values. Otherwise, it will demonstrate regions clustered with low attribute values.

\subsubsection{Location Selection Model}

The distribution of the return locations of overseas high-level young returned talent in China displays significant discretization characteristics. Hence, the Poisson regression model was selected to measure the influencing factors. Specifically, the number of returnees in each research unit from 2011 to 2016 was selected as the explained variable. Then, the dynamics of the professionals' motivation in choosing the relocation city was calculated. However, the Poisson regression model assumes that the mean value of the count dependent variable is equal to variance and to $\lambda_{i}$. For the counting data of non-independent events, the mean value of the dependent variable is far less than the variance; that is, there is a problem of over-dispersion in the sample, which causes the calculation results to deviate. Therefore, the negative binomial regression model was selected to describe the phenomenon $[55,56]$, as follows:

$$
\ln \lambda_{i}=\ln K_{i}+\text { offset }_{i}+\beta_{0}+\beta_{1} X_{1}+\beta_{2} X_{2}+\ldots+\beta_{i} X_{i}
$$

Based on the assumption that $Y_{i}$ obeys the Poisson distribution taking $\lambda_{i}$ as a parameter, the number of returned talent observed in every city $Y_{i}$ can be determined through the probability density function of the Poisson distribution as follows:

$$
\mathrm{P}=\left(\mathrm{Y}_{i}=y_{i} \mid X_{i}\right)=\operatorname{Exp}\left(-\lambda_{i}\right) \lambda_{i}^{y_{i}} / y_{i} !, \lambda>0, y_{i}=0,1, \ldots n,
$$

where: $K$ represents the degree of hyper dispersion, obeys the gamma distribution with mean value of 0 and variance of $\alpha$. The more significant $\alpha$ is, the higher the degree of hyper dispersion is [56].

As shown in Table 2, the status of urban amenity, academic opportunity, and place attachment in every city are employed as three independent variables to measure the driving factors for the location choice of overseas high-level young returned talent. 
Table 2. Overview of variable descriptions.

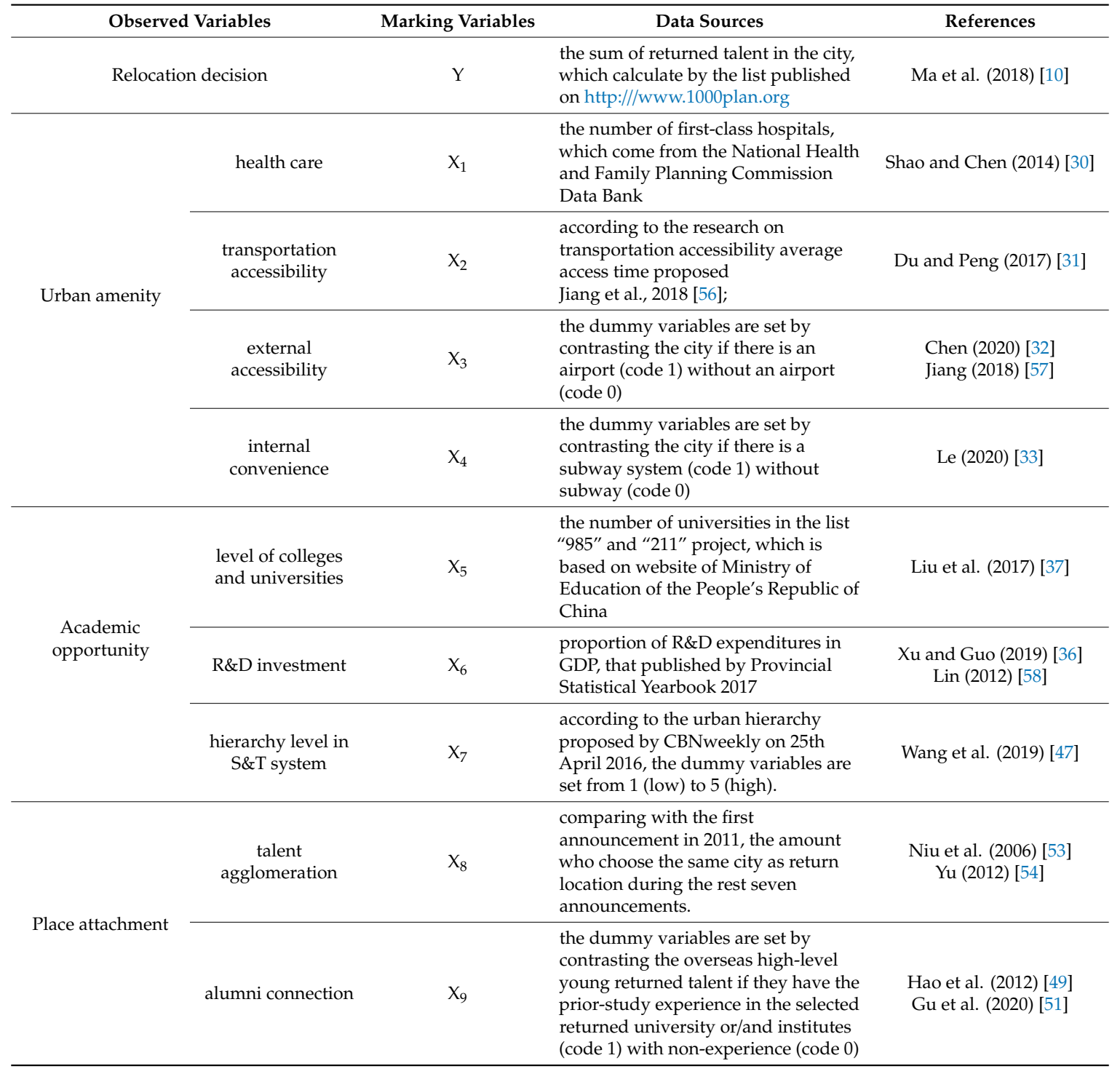

\section{Spatial Pattern of Location Choice of Overseas High-Level Young Returned Talent}

\subsection{Spatial Characteristics of Circumfluence Location}

Taking cities and overseas countries as basic space units, the study at first applied Moran's I index to explore the geographical agglomeration of relocation of overseas high-level young returned talent across the entire scale of China. The Moran's I index is 0.012 during the observation period, and the aggregation degree remained low. The overseas high-level young returned talent is mainly concentrated in some municipalities and provincial capital cities. At the regional level, the three largest circumfluence-pools for overseas high-level young returned talent are in the areas surrounding the Bohai Sea (27.63\%), the Yangtze River Delta (32.48\%), and the Pearl River Delta (8.63\%) (Figure 2). Specifically, China has a total of seven cities as the premium return choice: Beijing, Shanghai, Wuhan, Nanjing, Hangzhou, Hefei, and Guangzhou. Their convergence proportion accounts for $71.18 \%$ during 2011 to 2016. The other second- and third-tier cities in China continue to improve their innovation environments and have gradually turned into important return location choices, although the involved numbers are still small. 


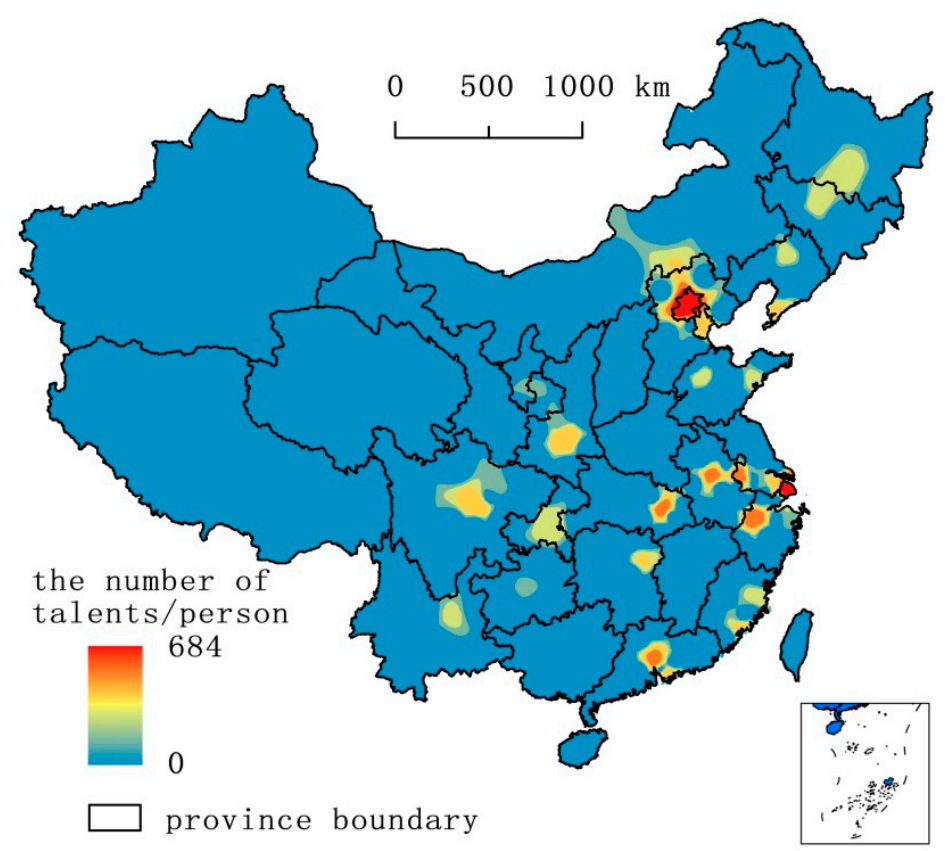

Figure 2. The overall spatial distribution of overseas high-level young returned talents in China (2011-2016).

\subsection{Analysis of Specialty Heterogeneity}

\subsubsection{Overseas High-Level Young Returned Talents Distribution by Majors}

Based on different academic fields, the distribution of China's overseas high-level young returned talent exhibits diverse spatial characteristics.

(1) The number of overseas high-level young returned talents shows a strong increase in all academic fields during the period under investigation. In particular, biological sciences, engineering, and materials sciences professionals comprise the main body of overseas high-level young talents, accounting for $26.55 \%$ and $25.29 \%$, respectively. This is due to the urgent need in the fields of biological sciences and new materials, which are more vital than ever. (2) There are 30 cities in the municipality and sub-provincial level, in which most of the overseas high-level young talents tend to choose to work. The overseas high-level young returned talents in the fields of biological sciences, information sciences, chemistry, environmental and earth science, engineering and materials science, and mathematical sciences are strongly concentrated in these 30 cities, accounting for $95.79 \%, 97.65 \%, 93.13 \%, 95.10 \%$, $94.06 \%$, and $97.52 \%$ respectively (Figure 3). (3) The spatial characteristics of the diverse academic fields show a similar pattern. More than $95 \%$ of the overseas high-level young returned talents chose the same cities mentioned above as their backflow location choice. The agglomeration and its involving path independence will rise up the Matthew effect and make the higher-level cities the favored choices when the overseas high-level young talents are motivated to return. 


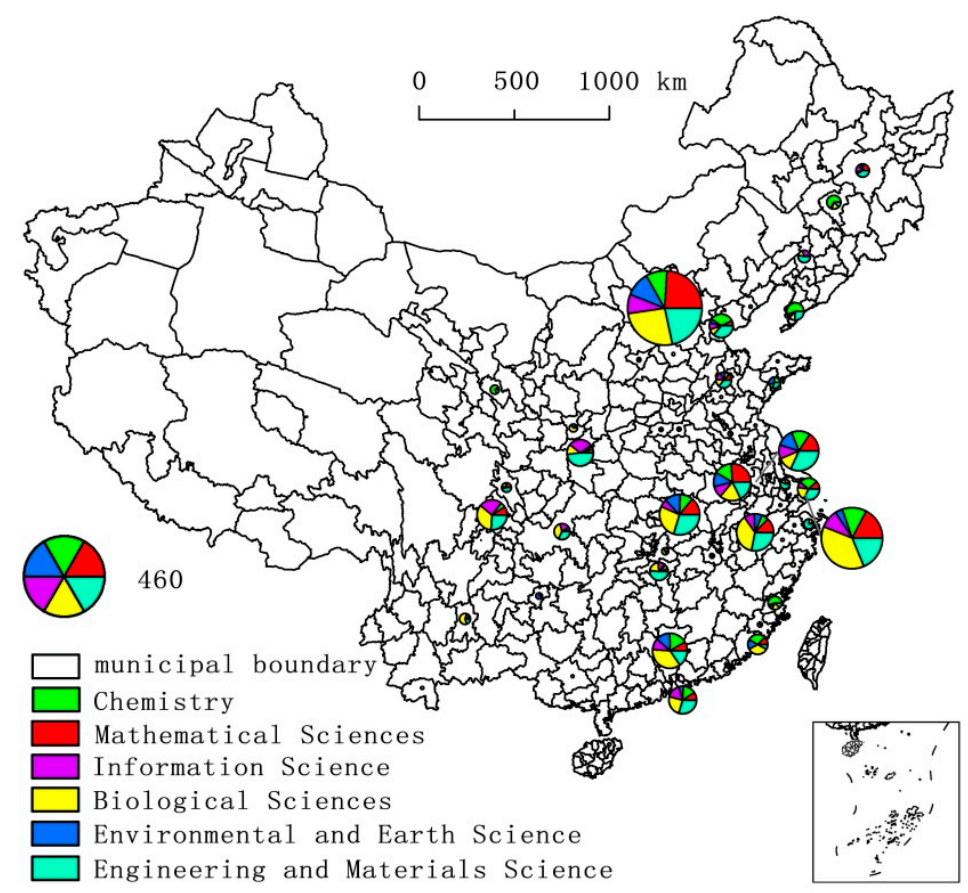

Figure 3. Spatial distribution of Chinese overseas high-level young returned talents by academic major (2011-2016).

\subsubsection{Spatial Distribution by Academic Major}

Through the above analysis, the distribution dynamics of hot spots were further calculated and analyzed by Getis-ord Gi* (Figure 4). The analysis reveals relatively clear features.
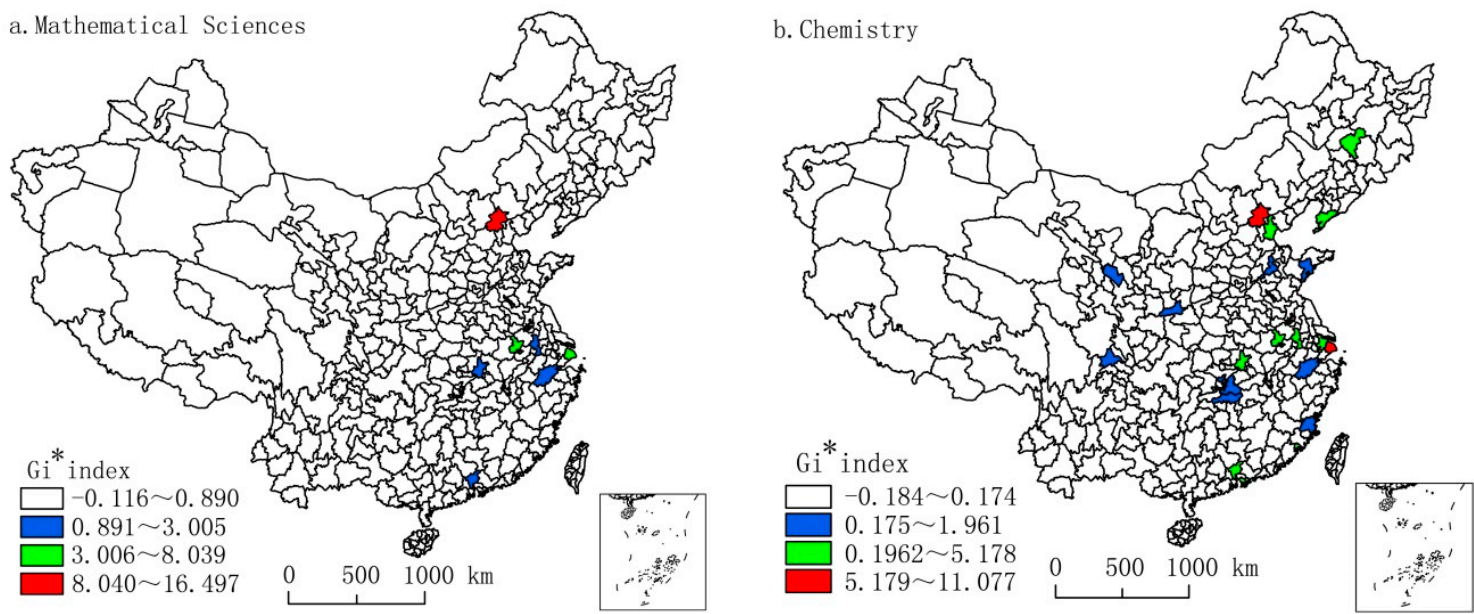

Figure 4. Cont. 

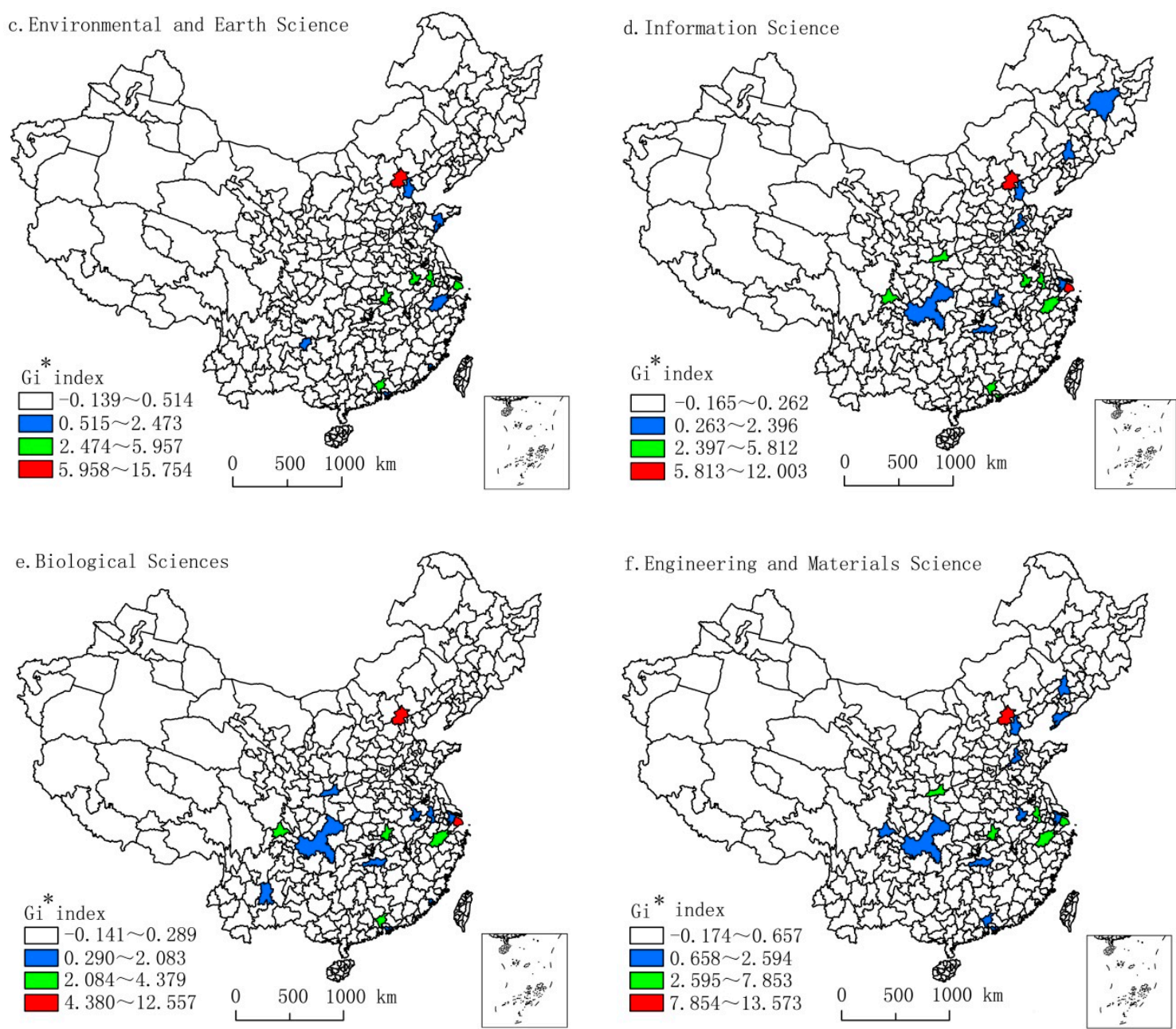

Figure 4. Spatial pattern of hotspot areas about Chinese overseas high-level young returned talents by major (2011-2016).

(1) Generally, the sum of hot spots is the least in all professional subjects, showing Beijing as the uppermost hot spot, and Shanghai and some province capitals as second-tier cities. This indicates a strong connection between the spatial structure of Chinese science and political resource allocation [20]. In particular, Beijing is shown as the core city that attracts overseas high-level young returned talent, owing to its numerous well-known universities, research institutes, innovation resource endowments, strong comprehensive competitiveness, and the best quality of life. (2) By comparison, the academic fields represented in Shanghai, shown as the first-level hotspot, are of great importance for more sub-hot cities, and the spatial character is scattered, as shown in Table 3. (3) These phenomena may be attributed to the spatial divergence caused by knowledge priority and legacies of China's Soviet-style innovation system. Science, Technology, Innovation (STI) science requires the specificity of coded knowledge that spans beyond spatial limits and is inclined to be located in knowledge hubs and global cities. Doing, Using, and Interacting (DUI) knowledge requires more tacit knowledge and is involved in more industrial cities. One cause has been, until recently, the legacy of China's Soviet-style S\&T system. China primarily attempted to replicate the Soviet Model to organize research institutes in several main cities to potentially provide well-trained engineers and new ideas to the local firms in industrial bases. 
Table 3. The proportion of hotspot regions and sub-hotspot regions based on different majors (2011-2016).

\begin{tabular}{|c|c|c|c|}
\hline & Subjects & Hotspot (\%) & Sub-Hotspot (\%) \\
\hline \multirow{3}{*}{ monocentric } & mathematical sciences & Beijing (37.25\%) & Shanghai (18.28\%), Hefei (9.93\%) \\
\hline & $\begin{array}{l}\text { environmental and earth } \\
\text { Science }\end{array}$ & Beijing $(29.80 \%)$ & $\begin{array}{c}\text { Nanjing }(11.43 \%) \text {, Wuhan }(10.61 \%), \\
\text { Hefei }(8.57 \%) \text {, Guangzhou }(8.16 \%) \text {, } \\
\text { Shanghai }(7.35 \%)\end{array}$ \\
\hline & $\begin{array}{l}\text { engineering and } \\
\text { materials science }\end{array}$ & Beijing (20.58\%) & $\begin{array}{c}\text { Shanghai }(12.02 \%) \text {, Nanjing }(8.56 \%) \text {, } \\
\text { Wuhan }(8.29 \%), \text { Hangzhou }(6.63 \%), \\
\text { Xian (5.94\%) }\end{array}$ \\
\hline \multirow{3}{*}{ polycentric } & chemistry & $\begin{array}{c}\text { Beijing }(15.78 \%) \\
\text { Shanghai }(15.27 \%)\end{array}$ & $\begin{array}{c}\text { Nanjing }(7.63 \%), \text { Hefei }(6.62 \%), \\
\text { Guangzhou }(6.36 \%), \text { Tianjin }(5.85 \%), \\
\text { Wuhan }(5.34 \%), \text { Dalian }(5.34 \%), \\
\text { Changchun }(4.07 \%) \text {, Suzhou }(4.07 \%), \\
\text { Shenzhen }(3.56 \%), \text { Xiamen }(3.56 \%)\end{array}$ \\
\hline & information science & $\begin{array}{l}\text { Beijing }(19.13 \%) \\
\text { Shanghai }(15.44 \%)\end{array}$ & $\begin{array}{c}\text { Chengdu }(9.40 \%), \text { Xian }(8.72 \%), \text { Nanjing } \\
(7.38 \%) \text {, Hefei }(5.70 \%), \\
\text { Guangzhou }(5.37 \%), \\
\text { Shenzhen }(5.37 \%), \text { Hangzhou }(5.03 \%)\end{array}$ \\
\hline & biological sciences & $\begin{array}{l}\text { Beijing }(23.42 \%) \\
\text { Shanghai }(23.03 \%)\end{array}$ & $\begin{array}{l}\text { Hangzhou (8.29\%), Wuhan (7.11\%), } \\
\text { Guangzhou (7.11\%), Chengdu (5.13\%) }\end{array}$ \\
\hline
\end{tabular}

\section{Factors Explaining the Return Choices of Overseas High-Level Young Returned Talent}

To obtain a clearer understanding of the spatial characteristics of the return choices, the study classifies the driving factors to produce the Poisson model regression result as shown in Table 4. Special emphasis is placed on the handling of multicollinearity; independent variables with a correlation greater than 0.50 were introduced into the model, and the negative binomial quasi-maximum likelihood estimation was selected as a method.

Table 4. Regression results of location choice of Chinese overseas high-level young returned talents (2011-2016).

\begin{tabular}{|c|c|c|c|c|c|}
\hline & Variable & Model 1 & Model 2 & Model 3 & Model 4 \\
\hline \multirow{4}{*}{ Urban amenity } & $X_{1}$ & $0.207^{* * *}$ & & & \\
\hline & $x_{2}$ & $0.538^{* * *}$ & 0.158 * & & \\
\hline & $x_{3}$ & & $0.860^{* * *}$ & & $0.987^{* * *}$ \\
\hline & $\mathrm{X}_{4}$ & & $4.619^{* * *}$ & & $4.446^{* * *}$ \\
\hline \multirow{3}{*}{$\begin{array}{l}\text { Academic } \\
\text { opportunity }\end{array}$} & $X_{5}$ & & \multirow{3}{*}{\multicolumn{3}{|c|}{$\begin{array}{l}0.252 \text { *** } \\
4.984^{* *} \\
1.662^{* * *}\end{array}$}} \\
\hline & $X_{6}$ & $4.804^{* * *}$ & & & \\
\hline & $x_{7}$ & & & & \\
\hline \multirow{2}{*}{$\begin{array}{c}\text { Place } \\
\text { attachment }\end{array}$} & $X_{8}$ & & \multirow{2}{*}{\multicolumn{2}{|c|}{$0.105^{* * *}$}} & \\
\hline & $X_{9}$ & & & & $0.014^{* * *}$ \\
\hline \multicolumn{2}{|c|}{$\mathrm{c}$} & $-2.846^{* *}$ & $-2.026^{* * *}$ & $-6.340^{* * *}$ & $-1.887^{* * *}$ \\
\hline \multirow{2}{*}{\multicolumn{2}{|c|}{$\begin{array}{l}\text { sample size } \\
\text { significance }\end{array}$}} & 264 & 264 & 264 & 264 \\
\hline & & 0.000 & 0.000 & 0.000 & 0.000 \\
\hline \multicolumn{2}{|c|}{ a } & $1.1677^{* * *}$ & $0.4331^{* * *}$ & $2.6752 * * *$ & $0.9082^{* * *}$ \\
\hline \multicolumn{2}{|c|}{ LR statistic } & $989.168^{* * *}$ & $2298.134^{* * *}$ & $1032.576^{* * *}$ & $1260.234^{* * *}$ \\
\hline
\end{tabular}

Note: ${ }^{*}$ significance at a level of $10 \% ;{ }^{* *}$ significance at a level of $5 \%$; ${ }^{* * *}$ significance at a level of $1 \%$.

Based on Table 4, the urban amenity is obviously reflected by the positive sign of the influence coefficients to overseas high-level young returned talent, including health care, transportation accessibility, external accessibility, and internal convenience. That is, Chinese overseas high-level young returned talent are inclined to locate in cities with better amenity as stated in hypothesis 1 . In particularly, relocation selection is more strongly related to the accessibility of urban transportation $\left(\beta \mathrm{x}_{4}=4.619\right.$ in model 2 and $\beta x_{4}=4.446$ in model 4 ). This highlights the fact that cities with better transportation systems normally belong to the city group (33 cities where have subway in end 2019) with ample 
technological resources and excellent urban infrastructure, which can bring about frequent exchanges and cooperation on economic, political, technological, cultural, human resources, informational, and other aspects. It is important to note that Chinese high-level cities can utilize all kinds of resources and offer better infrastructure condition. In view of enormous regional disparities, cities in relatively lower tiers suffer from a lack of overseas high-level young returned talent, and the gap of competence among different cities grows wider.

According to the result of model 1 and model 3, the factors of academic opportunity are positive and significant; that is, hypothesis 2 is correct. The specific variables in the innovation resource context are of particular interest. The $R \& D$ expenditures have shown a positive and extremely significant influence among all variables $\left(\beta x_{6}=4.804\right.$ in model 1 and $\beta x_{6}=4.984$ in model 3$)$ : the more a higher proportion of R\&D expenditures in GDP in a city, the more the likelihood ratio of returned talent. A plausible explanation is that highly ranked R\&D investment is concentrated in Beijing, Shanghai, or some provincial cities. Furthermore, universities, research institutes, and firms with high-level innovation coincidently gather in these cities. Therefore, overseas high-level young returned talent would acquire more financial support in all kinds of organizations in these cities. Hence, we can duly say that a large number of cities with high degrees of overlapped innovative resource agglomeration might be an intended consequence of pushing the high-level talent to relocate in the center of China's hierarchical city system.

As expected, the place-specific characteristics exert significant influence on the location choice; the variable is positive in Model $2\left(\beta x_{8}=0.105\right)$ and Model $4\left(\beta x_{9}=0.014\right)$, indicating that the higher the sum of talent agglomeration and alumni connection, the higher the probability of further return decisions will happen, as stated in hypothesis 3. Nevertheless, the influence coefficients of place attachment are close to zero.

Generally speaking, although these concepts differ in their focus, they explicitly address the fact that $\mathrm{H} 1, \mathrm{H} 2$, and $\mathrm{H} 3$ are accepted to a varying degree, which the variables are significant factors that drive the overseas high-level young returned talent to fulfill the relocation processes. Hence, building upon the results of the Poisson model, this study identifies how city-specific factors influence the variations in the location configuration of overseas high-level young returned talent which are, in order of importance, academic opportunity, urban amenity, and place attachment. Concretely, the most important factors for location choice of overseas high-level young returned talents, namely R\&D investment, internal convenience and hierarchy level in S\&T system, while external accessibility, transportation accessibility, university endowment, and health care are the substantial secondary factors. Eventually, place-oriented talent agglomeration and prior alumni connection play a minor role.

\section{Conclusions}

Examining returned talent data obtained from the "Thousand Youth Talents Plan" from 2011 to 2016, this study discusses the spatial pattern of overseas high-level young returned talent with a focus on city-level locations. The analysis results reveal the following.

(1) The backflow path of Chinese overseas high-level young returned talent presents a spatial structure as a transverse axis. The most important emigration source is the United States, and the main return locations in China are high-level cities such as municipalities or provincial capitals. Moreover, the distribution of returned talent within China has gradually turned into the "triple-core" pattern consisting of Beijing-Tianjin-Hebei, the Yangtze River Delta and the Pearl River Delta.

(2) The analysis of subject distribution revealed that the returned talent comprises relatively higher proportions in biological sciences, engineering, and materials. In particular, it is an unconscious coincidence that the academic fields that choose Shanghai as a first-level hotspot are of great importance for more sub-hot cities, and the spatial character is scattered. The phenomena may 
be attributed to the spatial divergence caused by knowledge priority and legacies of China's Soviet-style innovation system.

(3) Building upon the results of the Poisson model, this paper identifies how specific factors influence the variations in the location configuration of returned talent as well as the corresponding elements which are, in order of importance, academic opportunity, urban amenity, and place attachment. The results showed that most of the overseas high-level young returned talents tend to choose areas with higher R\&D investment and internal convenience, followed by external accessibility, and the hierarchy level in the science and technology system. The health care, transportation, accessibility level of colleges and universities, by contrast, are shown to have a smaller effect on the location of overseas high-level young returned talents, while the influence of talent agglomeration level and prior alumni connection are the least.

While this research provides some valuable insights into the return location of Chinese overseas high-level young returned talent, several limitations should be addressed in future research. On one hand, the empirical focus was on the initial location of young returned talent and did not examine the possible long-term mobility pathways. On the other hand, the overall backflow path of overseas high-level young returned talent is confined only to the foreign countries, rather than cities or specific universities and institutes, and hence displays a relatively rough spatial structure. Future studies should involve diving deeper into the data to trace the city network and its dynamical changes. Moreover, it should expand the view to other developing countries and integrate quantifiable data with knowledge outcomes and questionnaire information to add empirical evidence.

Author Contributions: H.J. conceived and designed the research, drafted and revised the manuscript, and discussed the results. W.Z. conceptualized and structured the paper. J.D. is the correspondence author, and discussed the results and revised the manuscript. All authors have read and agreed to the published version of the manuscript.

Funding: The research is supported by the National Natural Science Foundation of China (No. 41971160) and the Natural Science Foundation of Zhejiang Province (LY19D010009).

Acknowledgments: We greatly appreciate the helpful comments of reviewers and editors, which have significantly contributed to improving the quality of the paper.

Conflicts of Interest: The authors declare no conflict of interest.

\section{References}

1. Reiner, C.; Meyer, S.; Sardadvar, S. Urban attraction policies for international academic talent: Munich and Vienna in comparison. Cities 2017, 61, 27-35. [CrossRef]

2. Yin, Z.; Zhi, Q. Dancing with the academic elite: A promotion or hindrance of research production? Scientometrics 2017, 110, 17-41. [CrossRef]

3. Dai, O.; Liu, X.H. Returnee entrepreneurs and firm performance in Chinese high-technology industries. Int. Bus. Rev. 2009, 18, 373-386. [CrossRef]

4. Shi, Q.J.; Liu, T.; Musterd, S.; Cao, G.Z. How social structure changes in Chinese global cities: Synthesizing globalization, migration and institutional factors in Beijing. Cities 2017, 60, 156-165. [CrossRef]

5. Hagan, J.M.; Wassink, J.T. Return migration around the world: An integrated agenda for future research. Annu. Rev. Sociol. 2020, 46, 533-552. [CrossRef]

6. Sun, Y.T.; Guo, R.Y.; Zhang, S. China's brain gain at the high end: An assessment of thousand youth talents program. Asian J. Technol. Innov. 2017, 6, 274-294.

7. Saxenian, A. From brain drain to brain circulation: Transnational communities and regional upgrading in India and China. St. Comp. Int. Dev. 2005, 40, 35-61. [CrossRef]

8. Graaff, N.A. China Inc. goes global. Transnational and national networks of China's globalizing business elite. Rev. Int. Polit. Econ. 2020, 27, 208-233. [CrossRef]

9. Shen, Z.F.; Siraj, A.; Jiang, H.B.; Zhu, Y.M.; Li, J.J. Chinese-Style innovation and its international repercussions in the new economic times. Sustainability 2020, 12, 1859. [CrossRef] 
10. Ma, H.; Zhang, F.; Liu, Y. Transnational elites enhance the connectivity of Chinese cities in the world city network. Environ. Plan A 2018, 50, 749-751.

11. Mazzarol, T.; Soutar, G.N. Push-pull factors influencing international student destination choice. Int. J. Educ. Manag. 2002, 16, 82-90. [CrossRef]

12. Lin, D.M.; Zheng, W.; Lu, J.Y.; Liu, X.H.; Wright, M. Forgotten or not? Home country embeddedness and returnee entrepreneurship. J. World Bus. 2019, 54,1-13. [CrossRef]

13. Mao, G.; Hu, B.; Song, H. Exploring talent flow in Wuhan automotive industry cluster at China. Int. J. Prod. Econ. 2009, 122, 395-402. [CrossRef]

14. Cao, Z.; Zheng, X.; Liu, Y.; Li, Y.; Chen, Y. Exploring the changing patterns of China's migration and its determinants using census data of 2000 and 2010. Habitat Int. 2018, 82, 72-82. [CrossRef]

15. Chen, R.S.; Ye, C.; Cai, Y.L.; Xing, X.S.; Chen, Q. The impact of rural outmigration on land use transition in China: Past, present and trend. Land Use Pol. 2004, 40, 101-110. [CrossRef]

16. Liu, Y.; Shen, J. Jobs or amenities? Location choices of interprovincial skilled migrants in China, 2000-2005. Popul. Space Place. 2014, 20, 592-605. [CrossRef]

17. Bauder, H. The international mobility of academics: A labour market perspective. Int. Migr. 2015, 5, 83-96. [CrossRef]

18. Crescenzi, R.; Holman, N.; Orru', E. Why do they return? Beyond the economic drivers of graduate return migration. Ann. Regional Sci. 2017, 59, 603-627. [CrossRef]

19. Lee, E.S. A theory of migration. Demography 1966, 3, 47-57. [CrossRef]

20. Mountford, A. Can a brain drain be good for growth in the source economy? J. Dev. Econ. 1997, 53, $287-303$. [CrossRef]

21. Israel, E.; Cohen, N.; Czamanski, D. Return on capital? Determinants of counter-migration among early career Israeli STEM researchers. PLoS ONE 2019, 14, e0221882. [CrossRef]

22. Hidalgo, M.; Hernandez, B. Place attachment: Conceptual and empirical questions. Environ. Psychol. 2001, 21, 273-281. [CrossRef]

23. Li, M.; Bray, M. Cross-border flows of students for higher education: Push-pull factors and motivations of mainland Chinese students in Hong Kong and Macau. High. Educ. 2007, 53, 791-818. [CrossRef]

24. Clark, D.E.; Herrin, W.E.; Knapp, T.A.; Whit, N.E. Migration and implicit amenity markets: Does incomplete compensation matter? J. Econ. Geogr. 2003, 3, 289-307. [CrossRef]

25. Marans, R.W. Quality of urban life \& environmental sustainability studies: Future linkage opportunities. Habitat Int. 2015, 45, 47-52.

26. Rodriguez-Pose, A.; Ketter, T.D. Do local amenities affect the appeal of regions in Europe for migrants? J. Reg. Sci. 2012, 52, 535-561. [CrossRef]

27. Frenkel, A.; Bendit, E.; Kaplan, S. Residential location choice of knowledge-workers: The role of amenities, workplace and lifestyle. Cities 2013, 35, 33-41. [CrossRef]

28. Shi, W.; Du, D.; Yang, W. The flow network of Chinese scientists and its driving mechanisms based on the spatial development path of CAS and CAE academicians. Sustainability 2019, 11, 5938. [CrossRef]

29. Su, Y.; Hua, Y.; Liang, X. Toward job or amenity: Evaluating the locational choice of internal migrants in China. Int. Reg. Sci. Rev. 2019, 42, 400-430. [CrossRef]

30. Shao, L.; Chen, L. Study on the Allocation of human resources and Economic Growth in Northeast China; Economic Science Press: Beijing, China, 2014. (In Chinese)

31. Du, X.Q.; Peng, M.W. Do high-speed trains motivate the flow of corporate highly educated talents? Bus. Manag. J. 2017, 39, 89-107. (In Chinese)

32. Chen, X.X. Boosting interaction and communication: Dynamic mechanism of talent distribution and mobility in the United States. Soc. Constr. 2020, 7, 85-96. (In Chinese)

33. Chun, L. Experience and enlightenment of rail transit in promoting high-quality development of cities and towns. Zeng Ce Liao Wang 2020, 208, 49-51. (In Chinese)

34. De la Roca, J. Selection in initial and return migration: Evidence from moves across Spanish cities. J. Urban Econ. 2017, 100, 33-53. [CrossRef]

35. Chen, Q.; Li, Y. Mobility, knowledge transfer, and innovation: An empirical study on returned Chinese academics at two research universities. Sustainability 2019, 11, 6454. [CrossRef]

36. Guo, Y.Y.; He, Y.N.; Cheng, C.; Xu, Z.Y. The interaction mechanism between evolution of the roles S\&T intermediary plays and network structure in cluster. Stu. Sci. Sci. 2019, 37, 414-421, 461. (In Chinese) 
37. Liu, J.; Qu, C.Y.; Yang, H.C. The influencing factors of the aggregation of overseas top talents: An analysis based on the "Young Overseas High-level Talents Introduction Plan". Yuejiang Acade. J. 2017, 12, 78-85, 146-147. (In Chinese)

38. Zhang, W.; Chong, Z.; Li, X.; Nie, G. Spatial patterns and determinant factors of population flow networks in China: Analysis on Tencent Location Big Data. Cities 2020, 99, 102640. [CrossRef]

39. Zhou, Y.; Guo, Y.; Liu, Y. High-level talent flow and its influence on regional unbalanced development in China. Appl. Geogr. 2018, 91, 89-98. [CrossRef]

40. Gao, Z; Tisdell, C. China's reformed science and technology system: An overview and assessment. Prometheus 2004, 22, 311-331. [CrossRef]

41. Sun, Y.; Liu, F. New trends in Chinese innovation policies since 2009-A system framework of policy analysis. Int. J. Technol. Manag. 2014, 65, 6-23. [CrossRef]

42. Zhang, G.; Guan, J.; Liu, X. The impact of small world on patent productivity in China. Scientometrics 2014, 98, 945-960. [CrossRef]

43. Kroll, H.; Liefner, I. Spin-off enterprises as a means of technology commercialisation in a transforming economy-Evidence from three universities in China. Technovation 2008, 28, 298-313. [CrossRef]

44. Hong, W. Decline of the center: The decentralizing process of knowledge transfer of Chinese universities from 1985 to 2004. Res. Policy 2008, 37, 580-595. [CrossRef]

45. Andersson, D.E.; Gunessee, S.; Matthiessen, C.W. The geography of Chinese science. Environ. Plan A 2014, 46, 2950-2971. [CrossRef]

46. Liefner, I.; Jessberger, S. The use of the analytical hierarchy process as a method of comparing innovation across regions: The examples of the equipment manufacturing industries of Shanghai and Xiamen, China. Environ. Plan A 2016, 48, 1188-1208. [CrossRef]

47. Wang, R.Y.; Xue, D.S.; Liu, Y.; Huang, X. Spatial pattern change of high-educated talents in China based on Spatial Durbin Model. World Reg. Sci. 2019, 28, 134-143. (In Chinese)

48. Prazeres, L.; Findlay, A.; McCollum, D.; Sander, N.; Musil, E.; Krisjane, Z.; Apsite-Berina, E. Distinctive and comparative places. Alternative narratives of distinction within international student mobility. Geoforum 2017, 80, 114-122. [CrossRef]

49. Hao, J.; Welch, A. Hai Gui and Hai Dai: The job seeking experiences of high-skilled returnees to China. High Educ. Policy 2012, 25, 243-260. [CrossRef]

50. Boschma, R. Proximity and innovation: A critical assessment. Reg. Stud. 2005, 39, 61-74. [CrossRef]

51. Gu, H.; Meng, X.; Shen, T. China's highly educated talents in 2015: Patterns, determinants and spatial spillover effects. Appl. Spat. Anal. Policy 2020, 13, 631-648. [CrossRef]

52. North, D.C. Structure and Change in Economic History; Cheng, Y., Luo, H.P., Eds.; Shanghai People's Publishing House: Shanghai, China, 1991.

53. Niu, C.H.; Jie, M.; Zhang, M.; Duan, Z.P.; Li, G. The effect of talent accumulation and the assessment of it. China Soft Sci. J. 2006, 35, 118-123. (In Chinese)

54. Yu, B.B. Study on regional integration, cluster effect and high-level talents gathering-Based on the extension of push-pull theory. Refor. Econ. Sys. 2012, 38, 16-20. (In Chinese)

55. Lv, W.G.; Chen, W. Manufacturing industry enterprises location choice and the urban spatial restructuring in Nanjing. Acta Geogr. Sin. 2009, 64, 142-152. (In Chinese)

56. Bi, X.J.; Wang, M.F.; Li, J. Agglomeration and Suburbanization: A study on the spatial distribution of software industry and its evolution in metropolitan Shanghai. Acta Geogr. Sin. 2011, 66, 1682-1694. (In Chinese)

57. Jiang, H.N.; Xu, W.; Zhang, W.Z. Transportation accessibility and location choice of Japanese-funded electronic information manufacturing firms in Shanghai. Sustainability 2018, 10, 390. [CrossRef]

58. Lin, L. Research on the motivation of intellectual backflow in China. Develop. Econ. Res. 2013, 18, 267-285. (In Chinese)

Publisher's Note: MDPI stays neutral with regard to jurisdictional claims in published maps and institutional affiliations. 